\title{
Essential oil products of some medicinal plants as bio control agents against egg hatching and larval mortality of Meloidogyne incognita
}

\section{JOYMATI}

Department of Zoology, P.G. Centre, D.M. College of Science, Imphal,Manipur, India. Manoj Kumar Haodijammanoj63h@yahoo.in

\begin{abstract}
Petroleum ether extracts of six different medicinal plants Adhatoda vesica, Plumeria rubra, Mussenda globra, Mellia azedarach, Xylosoma longifolia and Andrographis panniculata were tested against egg and second stage juveniles of Meloidogyne incognita in terms of percentage of mortality and rate of inhibitory action in egg hatching. Among these six petroleum ether extracts leaves extracts of Andrographis panniulata was found most effective in both larval mortality and egg hatching followed by Mellia azedarach petroleum extracts. Although their effect in egg and larvae of $M$. incognita differ but these six petroleum ether extracts were found effective and can be used for the control of root knot nematode M. incognita @ JASEM
\end{abstract}

Plant parasitic nematodes cause disease of plant and lead to the lost of economically important plants. They can easily be controlled by application of chemical, physical, biological and cultural practices and land management practices and also by growing resistance varieties. Use of essential oils obtained from locally growing plants for nematode control practices has been tried out by different workers, Lela et al (1992) and Gokte et al (1991) etc. Thus the present investigation has been taken up to evaluate the nematicidal properties of petroleum ether extracts of leaves of six medicinal plants viz. Adhatoda vesica, Plumeria rubra, Mussenda globra, Mellia azedarach, Xylosoma longifolia and Andrographis panniculata against egg and second stage juveniles of $M$. incognita in terms of larval mortality and in egg hatching in vitro condition.

\section{MATERIALS AND METHODS}

a) Plant extract preparation: Healthy leaves of Adhatoda vesica, Plumeria rubra, Mussenda globra, Mellia azedarach, Xylosoma longifolia and Andrographis panniculata were collected. The collected plant parts were washed with water and the clean plant parts were oven dried at $58 \pm 2^{\circ} \mathrm{C}$ for 48 hours. The dried materials were made into powder with the help of a clean grinder, $20 \mathrm{gm}$ of each plant leaves powder were taken and placed in a thimble and extracted using organic solvents i.e. petroleum ether for 6 hours in a Soxhlet extraction unit (AOAC,1980) to a separate beaker. The solvent was completely evaporated from the extract in oven till it become a semisolid material. A stock solution of $1000 \mathrm{ppm}$ was prepared in distilled water with $1 \%$ Triton X-100 as emulsifier and from it further dilutions such as 1,10,100 and $1000 \mathrm{ppm}$ were prepared by adding required amount of distilled water.

b) Effect on egg hatching and larval mortality: One hundred eggs of $M$. incognita removed from infected roots of brinjal were transferred to a cavity block containing $5 \mathrm{ml}$ of oil extracts of different concentrations. Eggs put in distilled water were treated as control. All treatment was replicated three times. Mean egg hatching was counted at intervals of $12,24,48$ and 72 hours after the treatment In a similar experiment set up instead of eggs freely hatched second stage juveniles of $M$. incognita were transferred to the cavity block (100 juveniles/ cavity block) containing different concentration of oil extracts $(5 \mathrm{ml} /$ cavity block).

Juveniles put in distilled water were treated as control. There were three replication for each treatment .Juvenile mortality rate was counted at intervals of 12, 24, 48 and 72 hours after treatment. Those larvae which did not response to the touch by a fine needle were counted as dead.

\section{RESULTS AND DISCUSSION}

Effect of petroleum ether extracts obtained from leaves of six different medicinal plants viz. Adhatoda vesica, Plumeria rubra, Mussenda globra, Mellia azedarach, Xylosoma longifolia and Andrographis panniculata on eggs and second stage juveniles of $M$. incognita was shown in Table 1 and 2. Egg hatching was maximum in control although among treated one highest hatching rate was observed in $1 \mathrm{ppm}$ concentration at 48 hours in all these six plant extracts Table1. Among these six petroleum extracts, Andrographis panniculata extracts shows most inhibitory effect i.e 13, 1.7, 1 , 0,0 at 12 hours in all different concentration followed by Mellia azedarach extracts having 13, 2.4, 1.1, 1, 0 and Plumeria rubra extracts with hatching rate of $13,2.5,1.3,1$ and 0 . Rate of hatching was maximum at 48 hours and minimum at 12 hours which shows that hatched rate was directly proportional with exposure period. Rate of hatching was inversely proportional with concentration of extracts as it was decreased with increase in extract concentration as highest rate observed in $1 \mathrm{ppm}$ and lowest rate at $1000 \mathrm{ppm}$ concentration in oil extracts tested. 
Table 1: Effect of the essential oil extracts of six medicinal plants on egg hatching of M.incognita (The value is mean of 3 replications)

\begin{tabular}{|c|c|c|c|c|c|c|}
\hline \multirow[t]{3}{*}{ Plant } & \multirow[t]{2}{*}{ Duration } & \multicolumn{5}{|c|}{ Percentage of egg hatching per extract concentration } \\
\hline & & 0 & $1 \mathrm{ppm}$ & $10 \mathrm{ppm}$ & $100 \mathrm{ppm}$ & $1000 \mathrm{ppm}$ \\
\hline & 12 & 13 & 8.4 & 7.1 & 5.2 & 4.2 \\
\hline \multirow[t]{3}{*}{ A. vesica } & 24 & 27 & 15.6 & 13.4 & 10.1 & 8.4 \\
\hline & 48 & 41 & 20.1 & 18.6 & 13.2 & 11.2 \\
\hline & 12 & 13 & 6.1 & 5.2 & 3.1 & 2.0 \\
\hline \multirow{3}{*}{ M. globra } & 24 & 27 & 13.9 & 11.1 & 8.4 & 6.5 \\
\hline & 48 & 41 & 17.8 & 14.3 & 11.2 & 10.1 \\
\hline & 12 & 13 & 5.1 & 3.4 & 2.5 & 1.6 \\
\hline \multirow{3}{*}{$X$. longifolia } & 24 & 27 & 12.4 & 9.2 & 7.6 & 5.2 \\
\hline & 48 & 41 & 16.1 & 13.8 & 10.4 & 8.6 \\
\hline & 12 & 13 & 2.5 & 1.3 & 1 & 0 \\
\hline \multirow[t]{3}{*}{ P. rubra } & 24 & 27 & 5.4 & 4.2 & 3.1 & 1.5 \\
\hline & 48 & 41 & 12.3 & 7.8 & 5.2 & 3.5 \\
\hline & 12 & 13 & 1.7 & 1 & 0 & 0 \\
\hline \multirow[t]{3}{*}{ A. panniculata } & 24 & 27 & 4.2 & 3.1 & 1 & 0 \\
\hline & 48 & 41 & 10.1 & 6.4 & 4.2 & 1 \\
\hline & 12 & 13 & 2.4 & 1.1 & 1 & 0 \\
\hline \multirow[t]{2}{*}{ M. azedarach } & 24 & 27 & 8.2 & 3.4 & 2.5 & 1 \\
\hline & 48 & 41 & 12.1 & 9.1 & 5.3 & 3.0 \\
\hline \multirow[t]{3}{*}{ C.D. $(5 \%)$} & & & $1.44^{*}$ & $0.73 *$ & $1.57^{*}$ & \\
\hline & & & $2.76^{* *}$ & $3.20 * *$ & $1.62 * *$ & $0.84 * *$ \\
\hline & & & $0.94 * * *$ & $2.84 * * *$ & $0.94 * * *$ & $0.73 * * *$ \\
\hline \multirow[t]{3}{*}{ C.D. $(1 \%)$} & & & $2.02 *$ & $1.02 *$ & $2.20^{*}$ & \\
\hline & & & $3.87 * *$ & $4.49 * *$ & $2.27 *$ & $1.17 * *$ \\
\hline & & & $1.32 * * *$ & $3.99 * * *$ & $1.32 * * *$ & $1.02 * * *$ \\
\hline
\end{tabular}

*C.D. for 12 hrs observation, ** C.D. for 24 hrs observation, *** C.D. for 48 hrs observation

Table 2: Effect of the essential oil extracts of six different medicinal plants on second stage juveniles of $M$. incognita. (The value is

\begin{tabular}{|c|c|c|c|c|c|c|}
\hline \multirow[t]{3}{*}{ Plant } & \multirow[t]{2}{*}{ Duration } & \multicolumn{5}{|c|}{ Percentage of larval mortality per extract concentration } \\
\hline & & 0 & $1 \mathrm{ppm}$ & $10 \mathrm{ppm}$ & $100 \mathrm{ppm}$ & $1000 \mathrm{ppm}$ \\
\hline & 12 & 3.4 & 24.2 & 34.1 & 50.3 & 80 \\
\hline \multirow[t]{3}{*}{ A. vesica } & 24 & 3.4 & 28.1 & 46.2 & 70 & 84.2 \\
\hline & 48 & 3.4 & 43.4 & 56.1 & 80.2 & 98.1 \\
\hline & 12 & 3.4 & 26.1 & 38.8 & 57.6 & 80.4 \\
\hline \multirow[t]{3}{*}{ M. globra } & 24 & 3.4 & 33.6 & 49.1 & 71.4 & 88.6 \\
\hline & 48 & 3.4 & 43.4 & 56.1 & 80.2 & 98.1 \\
\hline & 12 & 3.4 & 33.1 & 45.2 & 68.4 & 90.3 \\
\hline \multirow[t]{3}{*}{$X$. longifolia } & 24 & 3.4 & 38.6 & 60 & 79.6 & 94.0 \\
\hline & 48 & 3.4 & 50.4 & 52.1 & 84.1 & 100 \\
\hline & 12 & 3.4 & 50.3 & 70.2 & 90.3 & 100 \\
\hline \multirow[t]{3}{*}{ P. rubra } & 24 & 3.4 & 61.2 & 72.5 & 94.2 & 100 \\
\hline & 48 & 3.4 & 71.4 & 88.2 & 98.6 & 100 \\
\hline & 12 & 3.4 & 60.6 & 89.4 & 97.8 & 100 \\
\hline \multirow[t]{3}{*}{ A. panniculata } & 24 & 3.4 & 73.2 & 91.6 & 100 & 100 \\
\hline & 48 & 3.4 & 84.8 & 95.2 & 100 & 100 \\
\hline & 12 & 3.4 & 51.4 & 73.5 & 93.2 & 100 \\
\hline \multirow[t]{2}{*}{ M. azedarach } & 24 & 3.4 & 62.6 & 78.1 & 95.6 & 100 \\
\hline & 48 & 3.4 & 74.8 & 90.4 & 100 & 100 \\
\hline \multirow[t]{3}{*}{ C.D. $(5 \%)$} & & & $0.84 *$ & $0.94 *$ & $1.46^{*}$ & $1.19 *$ \\
\hline & & & $0.94 * *$ & $1.26^{* *}$ & $1.10^{* *}$ & $2.01 * *$ \\
\hline & & & $1.03 * * *$ & $1.26^{* * *}$ & $1.26^{* * *}$ & $1.26^{* * *}$ \\
\hline \multirow[t]{3}{*}{ C.D. (1\%) } & & & $1.17 *$ & $1.32 *$ & $2.05 *$ & $1.67^{*}$ \\
\hline & & & $1.32 * *$ & $1.77 * *$ & $1.55 * *$ & $2.82 * *$ \\
\hline & & & $1.45 * * *$ & $1.77 * * *$ & $1.77 * * *$ & $1.77 * * *$ \\
\hline
\end{tabular}

*C.D. for 12 hrs observation, ** C.D. for 24 hrs observation, *** C.D. for 48 hrs observation

In terms of larval mortality also we get same results as that of hatching i.e. among these six tested plant oil extracts, Andrographis panniculata oil extracts was found cent percent larval mortality within 12 hours followed by Mellia azedarach extracts which shows $98 \%$ and Plumeria rubra shows $95 \%$ (Table 2). Among these tested six plant species oil extracts obtained from Adhatoda vesica was found least effective against $M$. incognita in terms of juvenile mortality in comparison with others. Rate of mortality was directly proportional with exposure period and concentration of extracts being maximum at 48 hours in $1000 \mathrm{ppm}$ concentration of all oil extracts. Thus, among these six plant species oil extracts obtained from Adhatoda vesica was least effective on juvenile mortality as well as on egg hatching. 
The present investigation are in adjustable conformity with the findings of Chandravadana et al (1996) who tested twenty one oil extracts obtained from 12 edible plants species against root knot nematode larvae in terms of their mortality rate and found effective. The work also supported the findings of Nidiry et al (1994) who investigated seed extracts of $G$. superba against $M$. incognita juvenile for their larval mortality and found inhibitory effect. Recently Saravanpriya and Sivakumar (2005) also tried out different methanol extracts of plant against $M$. incognita and found effective. Thus from the above findings it can be concluded that the incorporation of plant products such as oil of pre selected plants could provide a suitable and cheaper alternative for management of $M$. incognita and such method of nematode management can also applied in field studies also.

Acknowledgement: The author greatly acknowledged to the Head, Department of Zoology and Principle, DMC of Science for providing laboratory facility during the course of studies.

\section{REFERENCE}

Chandravadana, M U; Sebastian, E; Nidiery, J; Lella, N K; Parvatha Reddy, P; Khan, R.M; Rao, MS (1996). Nematicidal activity of some plant extracts. Indian. J. Nematol 26 (2):148151

Gokte, N; Maheshwari, M.L. and Mathur, U.K (1991). Activity of few essential oils against root knot and cyst nematode species. Indian J. Nematol.21(2): 123-127

Lella, N.K; Khan, R.M; Reddy, P.P.; Nidiry, E.S.J. (1992). Nematicidal activity of essential oils of Pelargonium gravelens against root knot nematode. Nematol Medit. 20: 57-58

Nidiry, E.S.J; Chandravadana, M.V; Khan, R.M.; Rao, M.S. (1994). In vitro nematicidal activity of the extracts of bulbs and seeds of onion against root knot nematode $M$. incognita. Nematol Medit.22: 37-40

Saravanpriya, B; Sivakumar, M (2005). HPLC Analysis of different plant extracts exhibiting nematicidal activity. Indian J. Nematology 35(1): 51-53 